\title{
Transcatheter arterial chemoembolization combined with radiofrequency or microwave ablation for hepatocellular carcinoma: a review
}

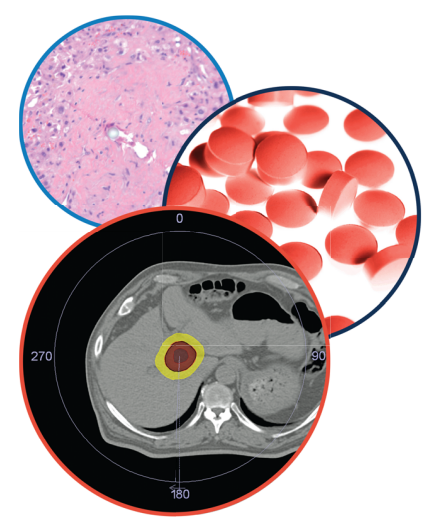

Hepatic Oncology

\author{
Nikolaos Galanakis", Elias Kehagias", Nikolas Matthaiou¹, Dimitrios Samonakis² \& Dimitrios \\ Tsetis*,1 \\ ${ }^{1}$ Interventional Radiology Unit, Department of Radiology, University Hospital of Heraklion, Faculty of Medicine, University of Crete, \\ Heraklion, P.C. 71110, Greece \\ ${ }^{2}$ Department of Gastroenterology, University Hospital of Heraklion, Faculty of Medicine, University of Crete, Heraklion, \\ P.C. 71110, Greece \\ *Author for correspondence: Tel.: +30 2810392 033, 392 534; Fax: +30 2810392 460; tsetisd@uoc.gr
}

Hepatocellular carcinoma (HCC) is the sixth most common type of malignancy. Several therapies are available for HCC and are determined by stage of presentation, patient clinical status and liver function. Localregional treatment options, including transcatheter arterial chemoembolization, radiofrequency ablation or microwave ablation, are safe and effective for HCC but are accompanied by limitations. The synergistic effects of combined transcatheter arterial chemoembolization and radiofrequency ablation/microwave ablation may overcome these limitations and improve the therapeutic outcome. The purpose of this article is to review the current literature on these combined therapies and examine their efficacy, safety and influence on the overall and recurrence-free survival in patients with HCC.

First draft submitted: 31 December 2017; Accepted for publication: 19 June 2018; Published online: 28 September 2018

Keywords: hepatocellular carcinoma - microwave ablation • radiofrequency ablation • transcatheter arterial chemoembolization

Hepatocellular carcinoma (HCC) is the sixth most common type of malignancy and the third most common cause of cancer-related death [1]. HCC is more frequent in males (2.4:1), with high incidence in southeastern Asia, middle and west Africa and Micronesia [2]. The incidence of HCC is increasing worldwide because of the increasing prevalence of hepatitis virus $\mathrm{B}(\mathrm{HBV})$ and $\mathrm{C}(\mathrm{HCV})$ infection [3]. The main risk factors for HCC are cirrhosis, $\mathrm{HBV} / \mathrm{HCV}$ infection, alcohol abuse and metabolic syndrome [4]. Other predisposing conditions for HCC development include cigarette smoking [5], iron overload disorders such as thalessemia, hemochromatosis [6], use of oral contraceptive pills [7] and consumption of alfatoxin (produced by Aspergillus species) -contaminated foods in warm and humid rural areas [8].

HCC is associated with a high mortality rate, so surveillance programs have been implemented in order to screen high-risk individuals, which is more cost-effective than the treatment of HCC. Patients who are at high risk for HCC development are patients with cirrhosis of different causes (HBV/HCV infection, alcohol, primary biliary cirrhosis), Asian male HBV carriers older than 50 years, and HBV carriers with a known family member with HCC, and they should be evaluated with ultrasound (US) every 6 months [9]. The outcome will be significantly improved if treatment is initialized at an earlier stage. Early-stage HCC lesions are small and curable in the majority of cases with minimally invasive methods, so early diagnosis is critical for therapy.

\section{Diagnosis}

Several modalities are available for HCC screening, including both serological and radiological tests. The most common biomarkers for HCC include AFP, des- $\gamma$ carboxyprothrombin and L3 fraction of AFP. For many years, AFP has been used for the detection of HCC with variable sensitivity and specificity [10,11]. Its level is increased

Future Medicine 
in patients with cirrhosis complicated by HCC but it is also elevated during pregnancy, in chronic hepatic disease without cirrhosis, in acute or chronic viral hepatitis and in various types of malignancies [12,13]. On the other hand, some small HCC tumors do not secrete AFP and the serum levels of AFP are normal [14]. For these reasons, AFP cannot be used to differentiate HCC from benign liver diseases or other malignancies and the current guidelines of the American Association for the study of Liver Diseases do not recommend AFP for screening or diagnostic purposes, and surveillance needs to be based on US examination every 6 months [9]. Over the recent years, the development of molecular biology has led to identification of new markers such as des- $\gamma$ carboxyprothrombin, glypican-3, squamous cell carcinoma antigen, human hepatocyte growth factor, $\gamma$-glutamyl transferase, VEGF and L3 fraction of AFP, which can be used for HCC detection and estimation of treatment success [15].

Different imaging studies are used for detection of HCC lesions. US is an operator and equipment-dependent modality. It is highly specific (97\%; range: $95-98 \%)$ to detect HCC but insufficiently sensitive (60\%; range: $44-$ 76\%) [16]. US can detect small tumors with a diameter of $1 \mathrm{~cm}$ but sometimes small HCC nodules less than $2 \mathrm{~cm}$ can be missed during a US examination [17]. The accuracy and sensitivity of multidetector computed tomography (CT) in the identification of HCC is very high. Usually, the lesion enhances vividly during late arterial phase and then washes out rapidly during portal venous phase, becoming hypoattenuating compared with normal liver parenchyma. Moreover CT is useful for the early diagnosis and the follow-up of the patients with HCC because it can identify lesions less than $2 \mathrm{~cm}$ in size with high sensitivity $[9,18,19]$. Magnetic resonance imaging (MRI) is also accurate in the early detection of HCC, and provides superior contrast resolution compared to CT. HCC lesions are varied hypo-, iso- or hyperintense in the $\mathrm{T} 1$ sequence and moderately hyper-intense in the $\mathrm{T} 2$ sequence. The lesions usually demonstrate arterial enhancement after gadolinium administration and become hypointense to the remainder of the liver during portal venous and delayed phases [20]. MRI is the most sensitive modality in differentiating the nature of regenerative nodules from HCC nodules in cirrhotic patients [21]. MRI is also useful in patients with renal impairment or hypersensitivity to CT contrast agents. On the other hand, it cannot be used in patients with pacemakers, ferromagnetic implants, claustrophobia and all common contraindications to MRI [22]. Liver Imaging Reporting and Data System is both a set of standardized terminology and a classification system for imaging findings in liver lesions. It was first introduced in 2011 and became widely accepted. It categorizes lesions according to their size and their characteristics (capsule presence, arterial phase enhancement, washout) into benign, HCC or alternative diagnosis. This classification system aims to decrease the variability in interpretation of liver lesions in high-risk patients [23].

The majority of HCCs are diagnosed at an intermediate to advanced stage, and less than $30 \%$ of patients with HCC are suitable for curative therapies such as surgical resection, radiofrequency ablation (RFA) or liver transplantation (LT) [24]. The median survival after diagnosis is 6-20 months [9]. Tumor staging is critical in treatment planning but prognosis is affected by the severity of liver dysfunction. The Child-Pugh classification system and the model for end-stage liver disease describe the severity of chronic liver disease but they do not assess cancer-related symptoms or the patient's clinical status [4]. The Barcelona-Clinic Liver Cancer (BCLC) staging system was based on the results from multiple cohort studies and randomized control trials (RCTs). It uses variables related to tumor stage, liver function status, physical status and cancer-related symptoms aiming to link the different stages with a treatment algorithm. This system has been recommended by liver societies from USA and Europe as the primary staging system for HCC because it provides accurate survival prediction and treatment allocation guidelines [25,26].

\section{Treatment of HCC}

Treatment options for HCC include surgical resection, LT, RFA, microwave ablation (MWA), cryoablation, systemic chemotherapy, transcatheter arterial chemoembolization (TACE), radioembolization and radiation therapy [27]. Despite the progress in imaging studies and serum biomarkers for HCC and the widespread use of surveillance programs for high-risk patients, the majority of HCC lesions are diagnosed at an intermediate to advanced stage when curative therapies such as surgical resection, LT, RFA or MWA are not possible [28]. Surgical resection is the gold standard treatment option for early-stage HCC in patients without cirrhosis or portal hypertension symptoms. It is associated with satisfactory survival with low recurrence rates and low perioperative mortality (2-3\%) [4].

Surgical resection increases the risk of hepatic decompression in cirrhotic patients, so it is important to estimate the residual liver function and the remnant liver volume [29-31]. Surgical resection is suggested in patients with early-stage disease and preserved liver function. Since the majority of HCC cases develop in cirrhotic patients, surgical intervention becomes challenging and the treatment is directed to other options. 
LT is a proper treatment option for patients with earlier stage HCC and end-stage liver disease. It has the significant advantage to eliminate both the tumor and the tumor-generating environment of cirrhosis, which predisposes to further carcinogenesis. The Milan criteria (single nodule up to $5 \mathrm{~cm}$, up to three nodules $<3 \mathrm{~cm}$, no evidence of extrahepatic spread or macrovascular invasion) are the traditional criteria for LT. Patients with HCC, within Milan criteria, who underwent LT had low rate of recurrence and significant long-term survival. However, these criteria are too stringent and exclude patients who may be suitable for LT. Expansion of Milan criteria has been studied by many centers with promising results as far as the recurrence and survival rates are concerned [32-35].

Systemic therapy for HCC is still under investigation. Until 2008, there was no systemic therapy to improve survival of patients with HCC. After the publication of two randomized Phase III trials, sorafenib is now the new standard treatment for advanced HCC. Sorafenib is an oral multityrosine kinase inhibitor, which inhibits multiple cell surface and downstream kinases and affects different pathway activations that are involved in tumor progression. Trials showed an increase in median overall survival with mild-to-moderate toxicity symptoms such as anorexia, nausea, weight loss, esthesia and hypertension $[36,37]$. Due to the relative chemotherapy-refractory nature of HCC and the subjacent poor liver function, systemic chemotherapy is not recommended for HCC. Other targeted molecular agents such as linifanib, brivanib or everolimus are under research or clinical development in order to treat patients who fail to tolerate sorafenib [38-40].

The role of radiotherapy for HCC has also evolved during the last years. External-beam radiotherapy can be used as a treatment option for diffuse HCC. However, it often causes radiation-induced liver disease due to the low radiation tolerance of the liver and is characterized by the lowest recommendation grade in the guidelines of EASL-EORTC [4,41]. On the other hand, stereotactic body radiotherapy (SBRT) is a noninvasive potentially curative method, which delivers high radiation dose to the target volume and minimal exposure to the surrounding healthy tissue. SBRT has comparable efficacy with other local therapies for nonresectable HCC but further studies are necessary to evaluate its indications, the optimal dose and the possible complications after SBRT [42].

Radioembolization is a potential therapeutic option for HCC and liver metastases. There are several available radioisotopes but the most commonly used is ${ }^{90} \mathrm{Y}$. Microspheres loaded with the radioactive compound are introduced percutaneously through a catheter into the target vessels and discharge local radiation with minimal exposure to the surrounding healthy tissues [43]. Different studies have shown promising efficacy and low risk for postembolization complications [44,45]. The National Cancer Institute states may recommend radioembolization in selected patients with HCC, who are not eligible for transplant or resection [46]. However, more randomized comparative studies are necessary to evaluate its role in the treatment of HCC.

Local-regional treatment for HCC such as RFA, MWA and TACE are promising therapeutic options for unresectable tumors. Combined treatments using both TACE and percutaneous ablation might overcome the disadvantages and limitations of the individual methods and improve the therapeutic outcome and survival of patients. The purpose of this article is to evaluate the efficacy and safety of combination treatments such as TACE + RFA and TACE + MWA in patients with HCC.

\section{Transcatheter arterial chemoembolization}

TACE is the recommended treatment option for patients with asymptomatic, large or multifocal HCC without macrovascular invasion or extrahepatic metastases in whom curative treatment is not indicated [47]. According to BCLC staging, TACE is suggested as the standard of care for intermediate stages HCC [9]. TACE was first introduced by Yamada et al. in 1977 [48]. The role of TACE depends on the isolation of HCC from its blood supply that is mainly derived from the hepatic artery in contrast with liver parenchyma, which is supplied from the portal vein. The embolization of the right hepatic artery branch results in tumor hypoxia and eventually necrosis [49]. A study from Golfieri et al. demonstrated significantly higher level of tumor necrosis in patients who underwent selective/superselective TACE compared with lobar TACE [50]. Conventional TACE uses a mixture of chemotherapeutic agents and lipiodol, whereas drug-eluting beads-TACE uses embolic microspheres loaded with a chemotherapeutic agent in order to minimize systemic toxicity and provide a standardized embolic effect [51]. A meta-analysis from Llovet and Bruix showed an improvement in 2-year survival with arterial embolization and a significant benefit of chemoembolization with cisplatin or doxorubicin in comparison with embolization alone [52] and a meta-analysis from Camma et al. indicated that TACE improved the overall 2-year survival in patients with unresectable HCC in comparison with nonactive treatment [53]. Lammer et al. demonstrated that drug-eluting beads-TACE improved tolerability and decreased liver toxicity in combination with higher rates of complete response [54]. However, TACE is often associated with minor complications such as fever, abdominal 
pain, nausea, leukocytopenia and impaired liver function. The risk of major complication such as irreversible liver failure, upper gastrointestinal bleeding, liver abscess, pulmonary embolism, occlusion of hepatic artery or acute renal failure is less than 5\% [55,56]. Absolute contraindication to TACE are portal vein thrombosis, biliary obstruction and encephalopathy, whereas relative contraindications include a bilirubin level more than $2 \mathrm{mg} / \mathrm{dl}$, a lactate dehydrogenase level more than $425 \mathrm{mg} / \mathrm{dl}$, and an aspartate aminotransferase level more than $100 \mathrm{IU} / \mathrm{l}$, which are associated with postprocedural mortality $[57,58]$.

\section{Radiofrequency ablation}

RFA is performed by advancing an especially designed electrode into the lesion and applying radiofrequency energy in order to create a zone of thermal destruction that encompasses the tumor. Temperatures range between 60 and $100^{\circ} \mathrm{C}$. RFA is moderated by the heat-sink effect (the convective cooling by adjacent blood vessels when ablated tissues are heated), which affects RFA results. Electrodes can be monopolar or bipolar in different designs and multiple sessions may be necessary for complete tumor ablation [59-61]. RFA is considered the best therapeutic modality for very early and early-stage HCC according to BCLC staging when resection or LT is not indicated. Patients must have a single nodule smaller than $5 \mathrm{~cm}$ in diameter or less than three nodules with a maximum diameter of $3 \mathrm{~cm}$, without vascular invasion or extrehepatic spread and good liver function status (Child-Pugh class A or B) [28,62]. Livraghi et al. showed that complete ablation of lesions less than $2 \mathrm{~cm}$ is possible in more than $95 \%$ of patients [63]. Brunello et al. also demonstrated the superiority of RFA compared with percutaneous ethanol injection, as far as complete response to treatment, on 139 patients with nodules less than $3 \mathrm{~cm}$ [64]. RFA efficacy is restricted by tumor size and location and the recurrence rate is higher in comparison with resection. Studies indicated that overall and disease-free survival was higher in patients who underwent surgical resection compared with RFA $[65,66]$. However, there are also studies that demonstrated significant initial response to RFA and improved overall and cancer-free survival in patients with nodules greater than $3 \mathrm{~cm}$ [67-69]. Major complications of RFA include intraperitoneal bleeding, infections, liver failure, pneumothorax, organ injury, bile duct stenosis and tumor lysis syndrome, but the major complication rate and procedural mortality rate is significantly low [70,71].

\section{Microwave ablation}

MWA uses electromagnetic energy to create an electromagnetic field that heats rapidly the target tissue and induces coagulation necrosis. In comparison with RFA, MWA is more homogenous and the heat-sink effect is reduced due to the higher temperatures and the faster heating that is produced by electromagnetic energy. On the other hand, the higher elevation of temperature in the MWA field can injure the adjacent structures [72-74]. The necrosis area has a form of round or column-like shape, depending on the microwave antenna used and the amount of power generated [75]. Indications and contraindication for MWA are similar to RFA apart from the size of tumors, as MWA can be used in 5-8 cm lesions. Earlier studies showed no significant difference in efficiency in comparison with RFA but recent studies showed an advantage of this method. Lloyd et al. demonstrated rapid ablation and low morbidity in patients who underwent MWA [76]. Another recent study which enrolled 221 patients showed high technique effectiveness rate and well tolerance from patients [77]. The major complications of MWA are bleeding, peritoneal hemorrhage, liver abscess, hemothorax, colon perforation and bile duct stenosis [78]. The recent improvements of MWA technology improved the efficacy of the treatment that allows faster and larger ablation areas.

\section{Combined TACE-RFA/MWA}

RFA, MWA and TACE have several limitations. RFA and MWA are curative for small tumors but their efficacy is limited in larger tumors. TACE is not restricted by tumor size, but it is not considered a curative method. The combination of these methods might improve the therapeutic outcome and prolong survival in patients with unresectable HCC. Buscarini et al. denoted that transcatheter arterial embolization can block hepatic arterial blood flow and attenuate the cooling effect of tumor blood flow, which is important in order to treat larger tumors that are not suitable for RFA alone [79]. Bloomston $e$ al. showed that combined TACE+RFA increased mean survival and 1-year survival compared with TACE alone [80]. On the other hand, Shibata et al. demonstrated that combined TACE + RFA had equivalent effectiveness with RFA alone for small $(<3 \mathrm{~cm})$ lesions without statistically significant changes in overall and event-free survival [81]. Another study indicated that complete response in lesions $3-5 \mathrm{~cm}$ can be achieved with TACE+RFA. They also introduced that the association with TACE provides a way to highlight lesions, which were not recognized through other imaging modalities and enabled further treatment of residual tumor in cases with large lesions [82]. Lee et al. also denoted the efficacy of RFA+TACE to treat small $(<2 \mathrm{~cm})$ 


\begin{tabular}{|c|c|c|c|c|c|}
\hline Study & (year) & Treatment & Number of patients & Tumor size $(\mathrm{cm})$ & Mean FUP (months) \\
\hline Buscarini et al. & (1999) & RFA + TACE & 14 & $3.8-6.8$ & 13.2 \\
\hline Shibata et al. & (2009) & $\begin{array}{l}\text { RFA + TACE } \\
\text { RFA }\end{array}$ & $\begin{array}{l}46 \\
43\end{array}$ & $0.8-3$ & 30.4 \\
\hline Lee et al. & (2009) & RFA + TACE & 14 & $0.8-2$ & 15 \\
\hline Hyun et al. & (2016) & RFA + TACE & 14 & $<2$ & 45.3 \\
\hline Yang et al. & (2009) & $\begin{array}{l}\text { RFA + TACE } \\
\text { RFA } \\
\text { TACE }\end{array}$ & $\begin{array}{l}31 \\
37 \\
35\end{array}$ & $1.2-8$ & 22 \\
\hline Cheng et al. & (2008) & $\begin{array}{l}\text { RFA + TACE } \\
\text { RFA } \\
\text { TACE }\end{array}$ & $\begin{array}{l}96 \\
100 \\
95\end{array}$ & $>3$ & 28.5 \\
\hline Veltri et al. & (2006) & RFA + TACE & 46 & $3-8$ & 15 \\
\hline Tang et al. & (2016) & $\begin{array}{l}\text { RFA + TACE } \\
\text { RFA } \\
\text { TACE }\end{array}$ & $\begin{array}{l}40 \\
49 \\
43\end{array}$ & $3-10$ & $\begin{array}{l}\text { NM, total FUP period was } \\
3 \text { years }\end{array}$ \\
\hline Seki et al. & (2000) & MWA + TACE & 18 & $2-3$ & 21.5 \\
\hline Yang et al. & (2009) & $\mathrm{MWA}+\mathrm{TACE}$ & 35 & $<3$ & NM, range: 6-31 \\
\hline Yi et al. & (2014) & $\begin{array}{l}\text { MWA/RFA + TACE } \\
\mathrm{MWA} / \text { RFA }\end{array}$ & $\begin{array}{l}47 \\
47\end{array}$ & $2-5$ & $\begin{array}{l}47.5 \\
47\end{array}$ \\
\hline Xu et al. & (2013) & $\begin{array}{l}\text { MWA + TACE } \\
\text { TACE }\end{array}$ & $\begin{array}{l}56 \\
80\end{array}$ & $5-12$ & 41 \\
\hline Liu et al. & (2011) & $\begin{array}{l}\text { MWA + TACE } \\
\text { TACE }\end{array}$ & $\begin{array}{l}16 \\
18\end{array}$ & $5.1-10.6$ & 8 \\
\hline
\end{tabular}

FUP: Follow-up; MWA: Microwave ablation; NM: Not mentioned; RFA: Radiofrequency ablation; TACE: Transcatheter arterial chemoembolization.

HCC lesions that were not visible on US or unenhanced CT [83], whereas Hyun et al. treated small HCC $(<2 \mathrm{~cm})$ in the caudate lobe with TACE and cone-beam CT-guided percutaneous RFA not amenable to US-guided RFA with satisfactory results [84]. Yang et al. showed that combined RFA+TACE was an effective treatment for recurrent HCC in patients after hepatectomy with better survival rates compared to monotherapies (RFA or TACE) [85]. A meta-analysis by Wang et el. that included six RCT studies from China and Japan and a total number of 534 patients showed that combination of TACE and RFA in comparison with RFA monotherapy was associated with greater overall survival $(\mathrm{HR}=0.62 ; \mathrm{p}<0.001)$ and recurrence-free survival $(\mathrm{HR}=0.55 ; \mathrm{p}<0.001)$, without differences in major complications [86]. Cheng et al. denoted that combined RFA+TACE improves survival in patients with HCC larger than $3 \mathrm{~cm}$. Patients were divided in three groups (RFA, TACE and combined TACE+RFA) and the rate of response to treatment and overall survival was higher in the combined TACE+RFA group [87]. Two seperate studies also showed that combination of TACE followed by RFA provided better local tumor control in patients with lesions more than $3 \mathrm{~cm}[88,89]$. In a recent study by Tang et al., 132 with unresectable HCC were allocated to three groups (RFA monotherapy, TACE monotherapy and combined TACE+RFA). The 3-year recurrence-free survival was higher in thecombined group ( 22.45 vs 20.93 vs $42.5 \%$, respectively) [90]. Finally, a recent systemic meta-analysis by Chen et al. composed of eight RCTs and 648 patients also showed that RFA+TACE is more effective than RFA, especially for intermediated and large HCC lesions with a higher overall hazard ratio (HR; HR $=0.6 ; \mathrm{p}<0.001)$ and recurrence-free survival $(\mathrm{HR}=0.58 ; \mathrm{p}=0.001)$ [91]. These findings are also confirmed by three several meta-analyses, which indicated that combined therapy was superior to monotherapy [92-94].

Combination of TACE and MWA improves both the efficacy of treatment and the total survival as it confirmed by several studies. Seki et al. demonstrated that combined MWA and TACE effectively treated lesions less than $3 \mathrm{~cm}$ without recurrence during follow-up and required a small number of microwave electrode insertions and 
irradiations. Apart from that, no major complications associated with the combined therapy were observed [95]. Yang et al. treated 35 patients with 41 nodules less than $3 \mathrm{~cm}$ with TACE followed by CT-guided MWA. Total necrosis of the tumor was observed in 34 nodules and incomplete necrosis in seven nodules as it was confirmed in CT scans and biopsies. During follow-up, there were two cases of recurrence [96]. A study from Yi et al. showed that TACE before RFA/MWA was more effective than RFA/MWA alone in patients with large HCC lesions less than $7 \mathrm{~cm}$. The patients in the combined TACE+RFA and TACE+MWA groups had better recurrence-free and total survival rate compared to monotherapy groups [97]. Xu et al. demonstrated that combined TACE+MWA prolonged overall survival in patients with large more than $5 \mathrm{~cm} \mathrm{HCC}$ without serious complications [98], whereas Liu et al. also showed that this technique is effective for tumor reduction with better survival rate compared to TACE alone in patients with large unresectable HCC lesions [99]. The patients underwent MWA at least 2 weeks after TACE. A recent study by Li et al. that included 3000 cases of HCC divided into two treatment groups (TACE+MWA and TACE,) showed a better complete tumor necrosis rate and a higher survival rate with the combined treatment [100]. The characteristics of the included studies (except meta-analyses) are shown in Table 1.

\section{Conclusion}

HCC is a common cause of malignancy worldwide. RFA or MWA are equivalent therapeutic options to surgical resection for small, early-stage HCC. TACE is a palliative therapy with satisfactory results for unresectable HCC. The limited necrosis induced by RFA or MWA and the irregular burn shape due to the heat-sink effect restricts the use of these therapies in intermediate and large lesions. The necrotic area of RFA/MWA may be increased with a combination of TACE, which might also reduce the chance of recurrence and improve the clearance of micrometastasis. As it is confirmed by several studies, the combination of these therapeutic options is superior to monotherapies, improving overall and recurrence-free survival, without significant difference in major complications between them.

\section{Future perspective}

HCC is an aggressive cancer contributing to major morbidity and mortality. Patients frequently present in advanced stages with concomitant liver dysfunction, which impedes curative therapies. Despite aggressive local treatments, recurrence and metastases decrease overall survival. Combining different therapies may further improve therapeutic outcomes. Future RCTs have to confirm these advantageous effects of combined therapies but also to clarify the optimal technique radiation dose and interval between TACE and RFA/MWA. Other ablative methods are also available for use, such as cryoablation, laser coagulation therapy and high-intensity focused US. Future studies may assess the combination of these ablative techniques with TACE or other therapies. Moreover, the use of new molecularly targeted agents in combination with local-regional treatments may also prolong survival, and it is a serious subject for further investigation. Despite these advances, there remains much to be learned about the risk factors, the histopathology and imaging features of HCC to succeed successful surveillance and earlier diagnosis, which is critical for HCC treatment.

\section{Executive summary}

- Hepatocellular carcinoma (HCC) is the sixth most common type of malignancy and the third most common cause of cancer-related death.

- Different modalities are available for HCC screening including both serological tests and imaging studies.

- Treatment of HCC depends on the preserved hepatic function, the clinical status of the patients and the tumor staging using the Barcelona-Clinic Liver Cancer staging system or other staging systems.

- Local-regional treatments for HCC such as radiofrequency ablation (RFA), microwave ablation (MWA) and transcatheter arterial chemoembolization (TACE) are promising therapeutic options but have limitations.

- TACE is the mainstay of treatment for unresectable HCC.

- RFA/MWA are suitable for small tumors but they do not achieve complete response in intermediate and large tumors.

- TACE can decrease blood flow to the tumor, making RFA/MWA more effective.

- Combination of TACE and RFA/MWA is associated with higher overall and recurrence-free survival, especially in intermediate and large tumors and should be considered as therapeutic option in early-stage HCC. 


\section{Financial \& competing interests disclosure}

The authors have no relevant affiliations or financial involvement with any organization or entity with a financial interest in or financial conflict with the subject matter or materials discussed in the manuscript. This includes employment, consultancies, honoraria, stock ownership or options, expert testimony, grants or patents received or pending, or royalties.

No writing assistance was utilized in the production of this manuscript

\section{Open access}

This work is licensed under the Attribution-NonCommercial-NoDerivatives 4.0 Unported License. To view a copy of this license, visit http://creativecommons.org/licenses/by-nc-nd/4.0/

\section{References}

1 Parkin DM, Bray F, Ferlay J, Pisani P. Global cancer statistics, 2002. CA Cancer J. Clin. 55(2), 74-108 (2005).

2 Ferlay J, Shin HR, Bray F, Forman D, Mathers C, Parkin DM. Estimates of worldwide burden of cancer in 2008: GLOBOCAN 2008. Int. J. Cancer 127(12), 2893-2917 (2010).

3 El-Serag HB. Hepatocellular carcinoma: an epidemiologic view. J. Clin. Gastroenterol. 35(5 Suppl. 2), S72-S78 (2002).

4 European Association for the Study of the Liver, European Organisation for Research and Treatment of Cancer. EASL-EORTC clinical practice guidelines: management of hepatocellular carcinoma. J. Hepatol. 56(4), 908-943 (2012).

5 Gandini S, Botteri E, Iodice S et al. Tobacco smoking and cancer: a meta-analysis. Int. J. Cancer 122(1), 155-164 (2008).

6 Kowdley KV. Iron, hemochromatosis, and hepatocellular carcinoma. Gastroenterology 127(5 Suppl. 1), S79-S86 (2004).

7 Maheshwari S, Sarraj A, Kramer J, El-Serag HB. Oral contraception and the risk of hepatocellular carcinoma. J. Hepatol. 47(4), 506-513 (2007).

8 Liu Y, Wu F. Global burden of aflatoxin-induced hepatocellular carcinoma: a risk assessment. Environ. Health Perspect. 118(6), 818-824 (2010).

9 Bruix J, Sherman M, American Association for the Study of Liver Diseases. Management of hepatocellular carcinoma: an update. Hepatology 53(3), 1020-1022 (2011).

10 Trevisani F, D'intino PE, Morselli-Labate AM et al. Serum alpha-fetoprotein for diagnosis of hepatocellular carcinoma in patients with chronic liver disease: influence of HBsAg and anti-HCV status. J. Hepatol. 34(4), 570-575 (2001).

11 Waghray A, Murali AR, Menon KN. Hepatocellular carcinoma: from diagnosis to treatment. World J. Hepatol. 7(8), 1020-1029 (2015).

12 Liu X, Cheng Y, Sheng W et al. Clinicopathologic features and prognostic factors in alpha-fetoprotein-producing gastric cancers: analysis of 104 cases. J. Surg. Oncol. 102(3), 249-255 (2010).

13 Sterling RK, Wright EC, Morgan TR et al. Frequency of elevated hepatocellular carcinoma (HCC) biomarkers in patients with advanced hepatitis C. Am. J. Gastroenterol. 107(1), 64-74 (2012).

14 Chen DS, Sung JL, Sheu JC et al. Serum alpha-fetoprotein in the early stage of human hepatocellular carcinoma. Gastroenterology 86(6), 1404-1409 (1984).

15 Zhao YJ, Ju Q, Li GC. Tumor markers for hepatocellular carcinoma. Mol. Clin. Oncol. 1(4), 593-598 (2013).

16 Colli A, Fraquelli M, Casazza G et al. Accuracy of ultrasonography, spiral CT, magnetic resonance, and alpha-fetoprotein in diagnosing hepatocellular carcinoma: a systematic review. Am. J. Gastroenterol. 101(3), 513-523 (2006).

17 Achkar JP, Araya V, Baron RL, Marsh JW, Dvorchik I, Rakela J. Undetected hepatocellular carcinoma: clinical features and outcome after liver transplantation. Liver Transpl. Surg. 4(6), 477-482 (1998).

18 Baron RL, Brancatelli G. Computed tomographic imaging of hepatocellular carcinoma. Gastroenterology 127(5 Suppl. 1), S133-S143 (2004).

19 Sangiovanni A, Manini MA, Iavarone $\mathrm{M}$ et al. The diagnostic and economic impact of contrast imaging techniques in the diagnosis of small hepatocellular carcinoma in cirrhosis. Gut 59(5), 638-644 (2010).

20 Willatt JM, Hussain HK, Adusumilli S, Marrero JA. MR Imaging of hepatocellular carcinoma in the cirrhotic liver: challenges and controversies. Radiology 247(2), 311-330 (2008).

21 Libbrecht L, Bielen D, Verslype C et al. Focal lesions in cirrhotic explant livers: pathological evaluation and accuracy of pretransplantation imaging examinations. Liver Transpl. 8(9), 749-761 (2002).

22 Attwa MH, El-Etreby SA. Guide for diagnosis and treatment of hepatocellular carcinoma. World J. Hepatol. 7(12), 1632-1651 (2015).

23 Mitchell DG, Bruix J, Sherman M, Sirlin CB. LI-RADS (Liver Imaging Reporting and Data System): summary, discussion, and consensus of the LI-RADS Management Working Group and future directions. Hepatology 61(3), 1056-1065 (2015).

24 Sangiovanni A, Del Ninno E, Fasani P et al. Increased survival of cirrhotic patients with a hepatocellular carcinoma detected during surveillance. Gastroenterology 126(4), 1005-1014 (2004). 
25 Llovet JM, Fuster J, Bruix J, Barcelona-Clinic Liver Cancer Group. The Barcelona approach: diagnosis, staging, and treatment of hepatocellular carcinoma. Liver Transpl. 10(2 Suppl. 1), S115-S120 (2004).

26 El-Serag HB. Hepatocellular carcinoma. N. Engl. J. Med. 365(12), 1118-1127 (2011).

27 Raza A, Sood GK. Hepatocellular carcinoma review: current treatment, and evidence-based medicine. World J. Gastroenterol. 20(15), 4115-4127 (2014).

28 Bruix J, Sherman M, Llovet JM et al. Clinical management of hepatocellular carcinoma. Conclusions of the Barcelona-2000 EASL conference. European Association for the Study of the Liver. J. Hepatol. 35(3), 421-430 (2001).

29 Kawano Y, Sasaki A, Kai S et al. Short- and long-term outcomes after hepatic resection for hepatocellular carcinoma with concomitant esophageal varices in patients with cirrhosis. Ann. Surg. Oncol. 15(6), 1670-1676 (2008).

30 Beard RE, Hanto DW, Gautam S, Miksad RA. A comparison of surgical outcomes for noncirrhotic and cirrhotic hepatocellular carcinoma patients in a Western institution. Surgery 154(3), 545-555 (2013).

31 Santambrogio R, Kluger MD, Costa M et al. Hepatic resection for hepatocellular carcinoma in patients with Child-Pugh's A cirrhosis: is clinical evidence of portal hypertension a contraindication? HPB (Oxford) 15(1), 78-84 (2013).

32 Mazzaferro V, Regalia E, Doci R et al. Liver transplantation for the treatment of small hepatocellular carcinomas in patients with cirrhosis. N. Engl. J. Med. 334(11), 693-699 (1996).

33 Mazzaferro V, Bhoori S, Sposito C et al. Milan criteria in liver transplantation for hepatocellular carcinoma: an evidence-based analysis of 15 years of experience. Liver transpl. 17(Suppl. 2), S44-S57 (2011).

34 Silva MF, Sherman M. Criteria for liver transplantation for HCC: what should the limits be? J. Hepatol. 55(5), 1137-1147 (2011).

35 Patel SS, Arrington AK, Mckenzie S et al. Milan Criteria and UCSF Criteria: a preliminary comparative study of liver transplantation outcomes in the United States. Int. J. Hepatol. 2012, 253517 (2012).

36 Cheng AL, Kang YK, Chen Z et al. Efficacy and safety of sorafenib in patients in the Asia-Pacific region with advanced hepatocellular carcinoma: a Phase III randomised, double-blind, placebo-controlled trial. Lancet Oncol. 10(1), 25-34 (2009).

37 Llovet JM, Ricci S, Mazzaferro V et al. Sorafenib in advanced hepatocellular carcinoma. N. Engl. J. Med. 359(4), 378-390 (2008).

38 Toh HC, Chen PJ, Carr BI et al. Phase 2 trial of linifanib (ABT-869) in patients with unresectable or metastatic hepatocellular carcinoma. Cancer 119(2), 380-387 (2013).

39 Finn RS, Kang YK, Mulcahy M et al. Phase II, open-label study of brivanib as second-line therapy in patients with advanced hepatocellular carcinoma. Clin. Cancer Res. 18(7), 2090-2098 (2012).

40 Zhu AX, Abrams TA, Miksad R et al. Phase 1/2 study of everolimus in advanced hepatocellular carcinoma. Cancer 117(22), 5094-5102 (2011).

41 Rim CH, Seong J. Application of radiotherapy for hepatocellular carcinoma in current clinical practice guidelines. Radiat. Oncol. J. 34(3), 160-167 (2016).

42 Sanuki N, Takeda A, Kunieda E. Role of stereotactic body radiation therapy for hepatocellular carcinoma. World J. Gastroenterol. 20(12), 3100-3111 (2014).

43 Memon K, Lewandowski RJ, Kulik L, Riaz A, Mulcahy MF, Salem R. Radioembolization for primary and metastatic liver cancer. Semin. Radiat. Oncol. 21(4), 294-302 (2011).

44 Kulik LM, Atassi B, Van Holsbeeck L et al. Yttrium-90 microspheres (TheraSphere) treatment of unresectable hepatocellular carcinoma: downstaging to resection, RFA and bridge to transplantation. J. Surg. Oncol. 94(7), 572-586 (2006).

45 Moreno-Luna LE, Yang JD, Sanchez W et al. Efficacy and safety of transarterial radioembolization versus chemoembolization in patients with hepatocellular carcinoma. Cardiovasc. Intervent. Radiol. 36(3), 714-723 (2013).

46 Thomas MB, Jaffe D, Choti MM et al. Hepatocellular carcinoma: consensus recommendations of the National Cancer Institute Clinical Trials Planning Meeting. J. Clin. Oncol. 28(25), 3994-4005 (2010).

47 Forner A, Llovet JM, Bruix J. Chemoembolization for intermediate HCC: is there proof of survival benefit? J. Hepatol. 56(4), 984-986 (2012).

48 Yamada R, Sato M, Kawabata M, Nakatsuka H, Nakamura K, Takashima S. Hepatic artery embolization in 120 patients with unresectable hepatoma. Radiology 148(2), 397-401 (1983).

49 Lewandowski RJ, Geschwind JF, Liapi E, Salem R. Transcatheter intraarterial therapies: rationale and overview. Radiology 259(3), 641-657 (2011).

50 Golfieri R, Cappelli A, Cucchetti A et al. Efficacy of selective transarterial chemoembolization in inducing tumor necrosis in small (<5 cm) hepatocellular carcinomas. Hepatology 53(5), 1580-1589 (2011).

51 Sieghart W, Hucke F, Peck-Radosavljevic M. Transarterial chemoembolization: modalities, indication, and patient selection. J. Hepatol. 62(5), 1187-1195 (2015).

52 Llovet JM, Bruix J. Systematic review of randomized trials for unresectable hepatocellular carcinoma: chemoembolization improves survival. Hepatology 37(2), 429-442 (2003). 
53 Camma C, Schepis F, Orlando A et al. Transarterial chemoembolization for unresectable hepatocellular carcinoma: meta-analysis of randomized controlled trials. Radiology 224(1), 47-54 (2002).

54 Lammer J, Malagari K, Vogl T et al. Prospective randomized study of doxorubicin-eluting-bead embolization in the treatment of hepatocellular carcinoma: results of the PRECISION V study. Cardiovasc. Intervent. Radiol. 33(1), 41-52 (2010).

55 Xia J, Ren Z, Ye S et al. Study of severe and rare complications of transarterial chemoembolization (TACE) for liver cancer. Eur. J. Radiol. 59(3), 407-412 (2006).

56 Brown DB, Nikolic B, Covey AM et al. Quality improvement guidelines for transhepatic arterial chemoembolization, embolization, and chemotherapeutic infusion for hepatic malignancy. J. Vasc. Interv. Radiol. 23(3), 287-294 (2012).

57 Berger DH, Carrasco CH, Hohn DC, Curley SA. Hepatic artery chemoembolization or embolization for primary and metastatic liver tumors: post-treatment management and complications. J. Surg. Oncol. 60(2), 116-121 (1995).

58 Marelli L, Stigliano R, Triantos $\mathrm{C}$ et al. Transarterial therapy for hepatocellular carcinoma: which technique is more effective? A systematic review of cohort and randomized studies. Cardiovasc. Intervent. Radiol. 30(1), 6-25 (2007).

59 Brace CL. Radiofrequency and microwave ablation of the liver, lung, kidney, and bone: what are the differences? Curr. Probl. Diagn. Radiol. 38(3), 135-143 (2009).

60 Goldberg SN, Gazelle GS, Mueller PR. Thermal ablation therapy for focal malignancy: a unified approach to underlying principles, techniques, and diagnostic imaging guidance. AJR Am. J. Roentgenol. 174(2), 323-331 (2000).

61 Poulou LS, Botsa E, Thanou I, Ziakas PD, Thanos L. Percutaneous microwave ablation vs radiofrequency ablation in the treatment of hepatocellular carcinoma. World J. Hepatol. 7(8), 1054-1063 (2015).

62 Crocetti L, De Baere T, Lencioni R. Quality improvement guidelines for radiofrequency ablation of liver tumours. Cardiovasc. Intervent. Radiol. 33(1), 11-17 (2010).

63 Livraghi T, Meloni F, Di Stasi M et al. Sustained complete response and complications rates after radiofrequency ablation of very early hepatocellular carcinoma in cirrhosis: Is resection still the treatment of choice? Hepatology 47(1), 82-89 (2008).

64 Brunello F, Veltri A, Carucci P et al. Radiofrequency ablation versus ethanol injection for early hepatocellular carcinoma: a randomized controlled trial. Scand. J. Gastroenterol. 43(6), 727-735 (2008).

65 Zhou Y, Zhao Y, Li B et al. Meta-analysis of radiofrequency ablation versus hepatic resection for small hepatocellular carcinoma. $B M C$ Gastroenterol. 10, 78 (2010).

66 Imai K, Beppu T, Chikamoto A et al. Comparison between hepatic resection and radiofrequency ablation as first-line treatment for solitary small-sized hepatocellular carcinoma of $3 \mathrm{~cm}$ or less. Hepatol. Res. 43(8), 853-864 (2013).

67 Choi D, Lim HK, Rhim H et al. Percutaneous radiofrequency ablation for early-stage hepatocellular carcinoma as a first-line treatment: long-term results and prognostic factors in a large single-institution series. Eur. Radiol. 17(3), 684-692 (2007).

68 Lin SM, Lin CJ, Lin CC, Hsu CW, Chen YC. Radiofrequency ablation improves prognosis compared with ethanol injection for hepatocellular carcinoma $<$ or $=4 \mathrm{~cm}$. Gastroenterology 127(6), 1714-1723 (2004).

69 Takahashi S, Kudo M, Chung H et al. Initial treatment response is essential to improve survival in patients with hepatocellular carcinoma who underwent curative radiofrequency ablation therapy. Oncology 72(Suppl. 1), 98-103 (2007).

70 De Baere T, Risse O, Kuoch V et al. Adverse events during radiofrequency treatment of 582 hepatic tumors. AJR Am. J. Roentgenol. 181(3), 695-700 (2003).

71 Livraghi T, Solbiati L, Meloni F, Ierace T, Goldberg SN, Gazelle GS. Percutaneous radiofrequency ablation of liver metastases in potential candidates for resection: the 'test-of-time approach'. Cancer 97(12), 3027-3035 (2003).

72 Brace CL. Microwave tissue ablation: biophysics, technology, and applications. Crit. Rev. Biomed. Eng. 38(1), 65-78 (2010).

73 Simon CJ, Dupuy DE, Mayo-Smith WW. Microwave ablation: principles and applications. Radiographics 25(Suppl. 1), S69-S83 (2005).

74 Ward RC, Healey TT, Dupuy DE. Microwave ablation devices for interventional oncology. Expert Rev. Med. Devices 10(2), 225-238 (2013).

75 Shibata T, Iimuro Y, Yamamoto Y et al. Small hepatocellular carcinoma: comparison of radio-frequency ablation and percutaneous microwave coagulation therapy. Radiology 223(2), 331-337 (2002).

76 Lloyd DM, Lau KN, Welsh F et al. International multicentre prospective study on microwave ablation of liver tumours: preliminary results. HPB (Oxford). 13(8), 579-585 (2011).

77 Wang T, Lu XJ, Chi JC et al. Microwave ablation of hepatocellular carcinoma as first-line treatment: long term outcomes and prognostic factors in 221 patients. Sci. Rep. 6, 32728 (2016).

78 Liang P, Yu J, Lu MD et al. Practice guidelines for ultrasound-guided percutaneous microwave ablation for hepatic malignancy. World J. Gastroenterol. 19(33), 5430-5438 (2013).

79 Buscarini L, Buscarini E, Di Stasi M, Quaretti P, Zangrandi A. Percutaneous radiofrequency thermal ablation combined with transcatheter arterial embolization in the treatment of large hepatocellular carcinoma. Ultraschall Med. 20(2), 47-53 (1999). 
80 Bloomston M, Binitie O, Fraiji E et al. Transcatheter arterial chemoembolization with or without radiofrequency ablation in the management of patients with advanced hepatic malignancy. Am. Surg. 68(9), 827-831 (2002).

81 Shibata T, Isoda H, Hirokawa Y, Arizono S, Shimada K, Togashi K. Small hepatocellular carcinoma: is radiofrequency ablation combined with transcatheter arterial chemoembolization more effective than radiofrequency ablation alone for treatment? Radiology 252(3), 905-913 (2009).

82 Gasparini D, Sponza M, Marzio A, Zanardi R, Bazzocchi M, Cemal Y. Combined treatment, TACE and RF ablation, in HCC: preliminary results. La Radiologia medica 104(5-6), 412-420 (2002).

83 Lee MW, Kim YJ, Park SW et al. Percutaneous radiofrequency ablation of small hepatocellular carcinoma invisible on both ultrasonography and unenhanced CT: a preliminary study of combined treatment with transarterial chemoembolisation. Br. J. Radiol. 82(983), 908-915 (2009).

84 Hyun D, Cho SK, Shin SW, Rhim H, Koh KC, Paik SW. Treatment of small hepatocellular carcinoma $(</=2 \mathrm{~cm})$ in the caudate lobe with sequential transcatheter arterial chemoembolization and radiofrequency ablation. Cardiovasc. Intervent. Radiol. 39(7), 1015-1022 (2016).

85 Yang W, Chen MH, Wang MQ et al. Combination therapy of radiofrequency ablation and transarterial chemoembolization in recurrent hepatocellular carcinoma after hepatectomy compared with single treatment. Hepatol. Res. 39(3), 231-240 (2009).

86 Wang X, Hu Y, Ren M, Lu X, Lu G, He S. Efficacy and safety of radiofrequency ablation combined with transcatheter arterial chemoembolization for hepatocellular carcinomas compared with radiofrequency ablation alone: a time-to-event meta-analysis. Korean J. Radiol. 17(1), 93-102 (2016).

87 Cheng BQ, Jia CQ, Liu CT et al. Chemoembolization combined with radiofrequency ablation for patients with hepatocellular carcinoma larger than $3 \mathrm{~cm}$ : a randomized controlled trial. JAMA 299(14), 1669-1677 (2008).

88 Kim JH, Won HJ, Shin YM et al. Medium-sized $(3.1-5.0 \mathrm{~cm})$ hepatocellular carcinoma: transarterial chemoembolization plus radiofrequency ablation versus radiofrequency ablation alone. Ann. Surg. Oncol. 18(6), 1624-1629 (2011).

89 Veltri A, Moretto P, Doriguzzi A, Pagano E, Carrara G, Gandini G. Radiofrequency thermal ablation (RFA) after transarterial chemoembolization (TACE) as a combined therapy for unresectable non-early hepatocellular carcinoma (HCC). Eur. Radiol. 16(3), 661-669 (2006).

90 Tang C, Shen J, Feng W et al. Combination therapy of radiofrequency ablation and transarterial chemoembolization for unresectable hepatocellular carcinoma: a retrospective study. Medicine 95(20), e3754 (2016).

91 Chen QW, Ying HF, Gao S et al. Radiofrequency ablation plus chemoembolization versus radiofrequency ablation alone for hepatocellular carcinoma: a systematic review and meta-analysis. Clin. Res. Hepatol. Gastroenterol. 40(3), 309-314 (2016).

92 Yan S, Xu D, Sun B. Combination of radiofrequency ablation with transarterial chemoembolization for hepatocellular carcinoma: a meta-analysis. Dig. Dis. Sci. 57(11), 3026-3031 (2012).

93 Lu Z, Wen F, Guo Q, Liang H, Mao X, Sun H. Radiofrequency ablation plus chemoembolization versus radiofrequency ablation alone for hepatocellular carcinoma: a meta-analysis of randomized-controlled trials. Eur. J. Gastroenterol. Hepatol. 25(2), 187-194 (2013).

$94 \mathrm{Gu}$ L, Liu H, Fan L et al. Treatment outcomes of transcatheter arterial chemoembolization combined with local ablative therapy versus monotherapy in hepatocellular carcinoma: a meta-analysis. J. Cancer Res. Clin. Oncol. 140(2), 199-210 (2014).

95 Seki T, Tamai T, Nakagawa $\mathrm{T}$ et al. Combination therapy with transcatheter arterial chemoembolization and percutaneous microwave coagulation therapy for hepatocellular carcinoma. Cancer 89(6), 1245-1251 (2000).

96 Yang WZ, Jiang N, Huang N, Huang JY, Zheng QB, Shen Q. Combined therapy with transcatheter arterial chemoembolization and percutaneous microwave coagulation for small hepatocellular carcinoma. World J. Gastroenterol. 15(6), 748-752 (2009).

97 Yi Y, Zhang Y, Wei Q et al. Radiofrequency ablation or microwave ablation combined with transcatheter arterial chemoembolization in treatment of hepatocellular carcinoma by comparing with radiofrequency ablation alone. Chin. J. Cancer Res. 26(1), 112-118 (2014).

98 Xu LF, Sun HL, Chen YT et al. Large primary hepatocellular carcinoma: transarterial chemoembolization monotherapy versus combined transarterial chemoembolization-percutaneous microwave coagulation therapy. J. Gastroenterol. Hepatol. 28(3), 456-463 (2013).

99 Liu C, Liang P, Liu F et al. MWA combined with TACE as a combined therapy for unresectable large-sized hepotocellular carcinoma. Int. J. Hyperthermia 27(7), 654-662 (2011).

$100 \mathrm{Li}$ W, Man W, Guo H, Yang P. Clinical study of transcatheter arterial chemoembolization combined with microwave ablation in the treatment of advanced hepatocellular carcinoma. J. Cancer Res. Ther. 12(Suppl.), C217-C220 (2016). 